\title{
Application of GIS Technologies in Optimal Routes Modelling of Water Utilities to Spur Development
}

\author{
Peter W Kathuo ${ }^{1}$, Kenneth Mubea ${ }^{1}$ \\ ${ }^{1}$ Institute of Geomatics, Geospatial Information Science and Remote Sensing, CBD Campus Nairobi \\ Dedan Kimathi University of Technology
}

\begin{abstract}
Mumoni District lies in the semi-arid zone and the erratic and unreliable rainfall has worsened the situations. The women and girls walk an average distance of $10-15 \mathrm{~km}$ in search of water. Lack of adequate access to basic education and also poor performance in schools is eminent. Global demand for water is projected to grow rapidly, in the developing countries, higher to a tune of 93\%. The objectives of this study was to carry out assessment and develop optimal route model of water utilities to spur development in Mumoni District, Kitui County in Kenya. in line with the Kenya vision 2030 i.e. to become a middle income country will be accelerated by working towards Sustainable Development Goals (SDG's) to reduce poverty, improve literacy, adequate access to basic needs and improved maternal health. The study employed the GIS and Remote sensing technologies to develop a geodatabase, assessment of the water utilities and modeling of the optimal routes (water networks) connecting all the schools. Analytical Hierarchy Process (AHP), a multi-criteria decision making (MCDM) method was used to generate judgment matrix based on the opinions of experts' opinion which were used in weighted overlay using ArcGIS software. A cost surface raster layer was generated by combining (weighted overlay) the various datasets which was then used to model the optimal routes (least cost path) by setting the reservoirs (existing water tanks) as the source layer and the schools locations as the destination layer. From the research, it was established that the existing water line serves the lower region only and the storage tanks are located approximately over 10km apart. Finally, this research has established that AHP and GIS technologies are more convenient and cost effective tools in modeling optimal routes, further it can be used in efficient and effective management of water supply systems.
\end{abstract}

Keywords: GIS, Network analysis, modeling, spatial analysis, AHP, Classification

\section{Introduction}

Water forms a critical component of the basic human needs. Mumoni District lies in the semi-arid zone and the recent erratic and unreliable rainfall has worsened the situation. The county also neighbours arid areas such as the Tana River County. The Main economic activities in the area are the small scale farming and the animal keeping. Over several decades, there has been great conflict as the communities compete for households and domestic water .The Mwingi National Game Reserve also lies in the area. Due to water scarcity and conflict over the limited resources, it has resulted to loss of life, poor food production not only for commercial purpose but also for domestic use. The land is fairly good for farming and if the situation can be improved through irrigation among other consideration, then, the socioeconomic development can be improved. The schools in the region (Mumoni) have continued to perform dismally due to the challenges of accessing water among other factors.

According to the World Health Organization (WHO), approximately 194 million school days would be realized if the millennium Development Goal for sanitation was achieved. When schools provide the students with adequate clean water, sanitation and hand washing facilities the overall performance will be tremendously improved. These adequate facilities entail an improved safe water source such as the piped water, borehole or even protected dug well [18].

\subsection{Background}

Though the global demand for water is projected to grow rapidly, in the developing world, the demand will be much higher to a tune of $93 \%$, additional demand and minimal increase in capacity especially in dry basins [14]. Mumoni sub-county has continued to perform poorly in increasing domestic earning to the people as well meeting the government goals of achieving education for all. The free primary education and the current plans for the government to introduce the free secondary education including increasing the capitation needs to be relooked considering other factors. Such other factors include but not limited to access to clean water in schools as well the homes where these pupils come from. This is because lack of adequate water in homes as well as in the schools will greatly affect the performance of the pupils as well improving the socioeconomic status.

Education for all and reducing the poverty index as envisaged in the sustainable development goals (SDG's). In view of the latter the quality and sustainability factors must be considered adopting the new technologies such as the geospatial technology to change our thinking and new way of doing things.

Mumoni District which was part of the area covered in the research mapping ground water potential in Kitui County [6]. From the finding the area of study Mumoni District falls in the least suitable region. It is worth noting that the area of study border with Tana River which is classified as arid area and there exist no distinct climatic boundary since climatic data is continuous and not discrete.

To Decrease the cost, time and minimal damage to environment depend on optimum route at beginning [20]. Route determination is a complex process in which variables are considered and simultaneously analyzed. In kenya and particular Kitui county the water network will reguire a more 


\section{International Journal of Science and Research (IJSR) \\ ISSN (Online): 2319-7064}

Index Copernicus Value (2013): 6.14 | Impact Factor (2014): 5.611

informed scientific method considering various variable and avoid use of manual method or skewed factors. Technical, economical, environmental and sociological issues should considered in routing.

\subsection{Analytical hierarchy process (AHP)}

In many real life situations a decision has to be made with certain degree of accuracy. To avoid biased decision hence high accuracy as well as improve on the results of the targeted products and maximize profits, an analytical hierarchy process has to be employed. AHP is a multi-criteria decision making process by Saaty in 1977 and 1994 to assist researchers and decision makers due it powerful tool, it employs tabulation and mathematical computation [17]. It involves use of pairwise comparisons of various items involved or under consideration to make a decision. The AHP method had and has shortcoming such reversing the alternatives and other critics but widely it remains the most acceptable method. in the study "usage of GIS,GPS, and Remote sensing data to identify effective and optimum route of development project like Road,Train and Canal for better E-governance implementation" by [15]. demonstrate how GIS and Remote sensing can used to improve route location hence cut cost and improve on e-governance.

\subsection{Route network analysis}

Geographic Information Systems (GIS)-based Customized systems to automate the process of optimum shortest path finding for routing of underground power supply cable between any two substations [19].In this paper the author combines the spatial analysis capabilities of GIS with the sophistication of one of the Artificial Intelligence technique "Simple Ant Colony Optimization" to deal with the complexity inherent in optimum shortest path finding. In the latter research the weightage to the routes Weightage (initial weightage) to the routes are assigned after consulting TNEB authorities of cable laying section, on considering the factors such as Road width, Land use, Traffic flow (high, medium, low), Congestion in the road, Road type (one way or two way), Cost etc. the research employed the powerful functionality of ArcGIS tools "the network analyst to validate the results. The automation of power transmission routes integrates a detailed geographic modeling of problems with information from expert knowledge [19]. Apart from the GIS other algorithms for route analysis include the heuristic search, dynamic programming technique, ant colony systems (ACS) among others. In this study road network, land use, traffic flow, congestion on the road, road type and cost were weighted. The most preferable and conventional place for cable laying is any side of the road. In arcinfo software there is a extension called network analyst to find the shortest path. To validate the proposed algorithm run by giving initial weightage as zero for all. The advantage of shortest path is it reduces the cost of material for pipes, labour and significantly reduces the transmission losses and provides the services in the shortest time possible.

\subsection{Point Location}

The point of Minimum Aggregate Travel (MAT) problem is an instance of location in continuous space and finds the location that minimizes total distances with respect to a number of points. The analogous problem on networks would involve finding the location on a network that minimizes total distances to a number of points also on the network. In network the Louis Hakimi theory proves that for this problem of minimizing the distance the only location that to be considered are the nodes. The MAT problem is also known as the 1-median problem and p-median problem which seeks the optimum location for any number of p-location such that the sum of distances between each weight and the nearest location/facility is minimized. The median seek to minimize the total distance travelled while the coverage problem seeks to minimize the furthest distance travelled.

\section{Problem Statement}

Water forms a critical component of the basic human needs. Mumoni District lies in the semi-arid zone and the recent erratic and unreliable rainfall has worsened the situation. The Main economic activities in the area are the small scale farming and the animal keeping. Over several decades, there has been great conflict as the communities compete for households and domestic water. The county also neighbours arid areas such as the Tana River County. The Mwingi National Game Reserve also lies in the area. Due to water scarcity and conflict over the limited resources, it has resulted to loss of life, poor food production not only for commercial purpose but also for domestic use. The land is fairly good for farming and if the situation can be improved through irrigation among other consideration, then, the socioeconomic development can be realized. The schools in the region (Mumoni) have continued to perform dismally due to the challenges of accessing water among other factors.

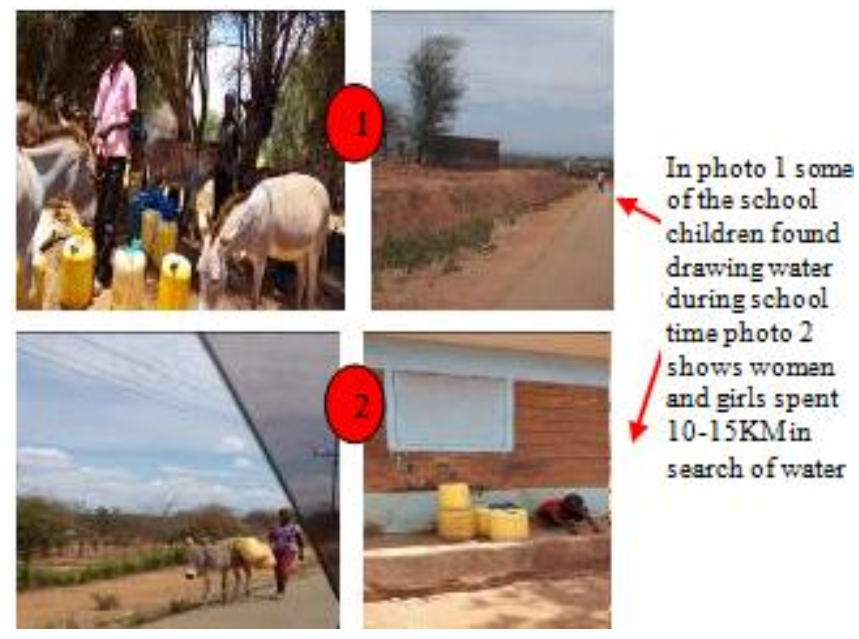

3. Methodology

\subsection{Study Area}

The study area is Mumoni District in Kitui County, Kenya. Kitui county borders with eight (8) other counties i.e. Tharaka Nithi, Isiolo, Meru counties to the North, Tanariver 


\section{International Journal of Science and Research (IJSR) \\ ISSN (Online): 2319-7064}

Index Copernicus Value (2013): 6.14 | Impact Factor (2014): 5.611

county eastern side, Taita Taveta and Makueni counties to the south and Machakos ,Embu and Makueni counties to the west.

\subsection{Mumoni District in Kitui County}

Mumoni District cover the former Kyuso District covering an area of about 1070sq KM with seven (7) locations and twenty one (21) sub locations. The study area ranges from longitude 37052'47'E and 38009'23'E while the latitude is 0014'50'S and $0045^{\prime} 04$ 'S. the study area population of 47,309 with an average of 2253 people per sub locations. The population constitute male 21951(46\%) and female is $25358(54 \%)$ [1]

Figure 3.1 show the location of the study area from the global perspective. Kenya lies in Africa continent and equator cut the country into two halves with longitute $34^{\circ}$ and $39^{\circ}$ approximately. Kitui County is one of the forty seven devolved units of governance. Mumoni District falls on the north western side of the Kitui County.

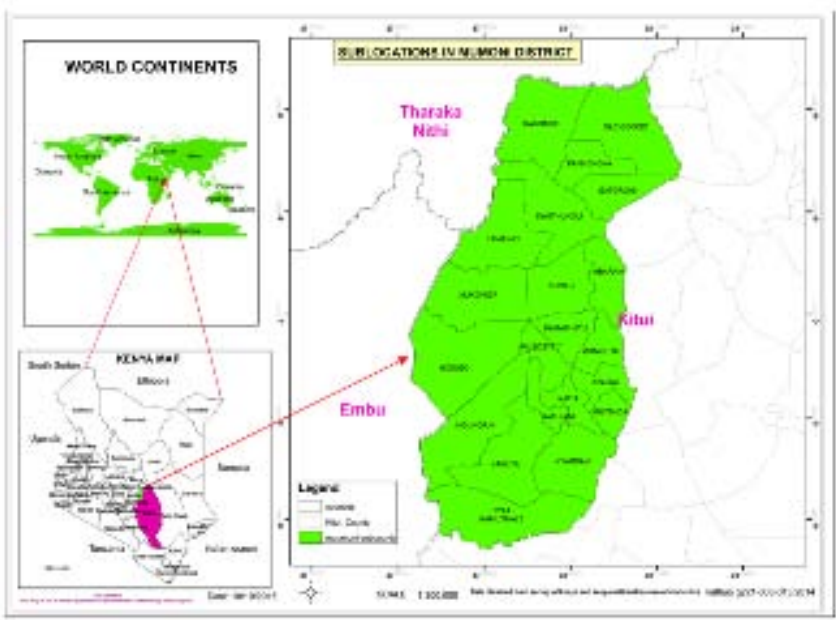

Figure 1: Location of the Study Area

\subsection{Data Gathering Procedure}

This study involved the use of both primary and secondary data. Mapping of the water utilities and schools as well as other factors considered was carried out. Sources of secondary data include the ministry of water, environment and natural resources. These include the existing boreholes, water lines and distribution points. The ministry has also information on non-spatial data such as hard copies of records such as dams name and the volume, and the expected life span. The main uses of water generated either domestic use, industrial or even agricultural uses. Primary data collection involved use of questionnaires, picking location data of water utilities

\subsection{Raster Data}

The main raster data used for remote sensing analysis were ASTER and SRTM data which were downloaded from the USGS website whose path is http://edcsns17.cr.usgs.gov/EarthExplorer/ or http://glovis.usgs.gov/
The satellite imagery Landsat 8 of May 2015 of twelve bands was used. Since the downloaded images were un-calibrated, data was viewed then it was calibrated to make it smooth then it was quantitatively analyzed. The raw data was radiometrically corrected using the USGS metadata file to use scientifically meaningful physical measurement. The Calibration Type was Reflectance while the Scale Factor was set to 10000.00 to reduce the size of the output file. The study area was covered by three images which were pansharpened separately using band 8 of the respective image and then mosaic was prepared. The mosaic image was then clipped using the shape file of the study area.

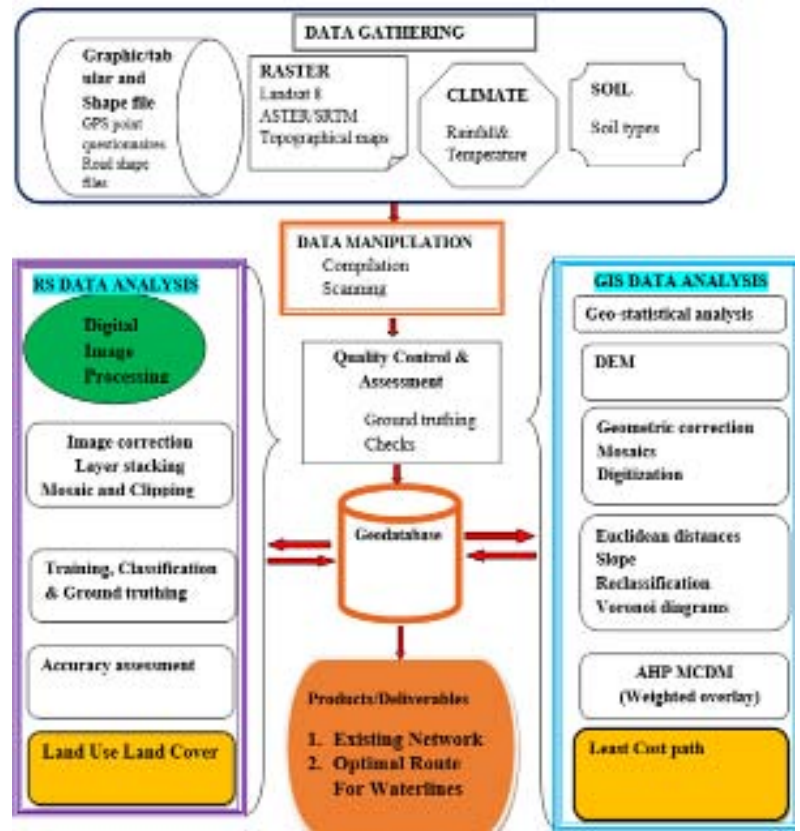

Figure 2: Methodology Schema

Scanning and Geo-referencing of the Topographical maps covering the area at scale of 1:50,000 acquired from survey Kenya were scanned and cropped to obtain area of interest after geo-referencing them. The map series no. 137/1,137/2, $137 / 3,136 / 2$ and 136/4 covered the area of study sufficiently.

The scanned maps were geo-referenced to conform to actual ground coordinates and the re-projected to one common system to enable overlay and various data analysis. Radiometric correction on raster images were carried out before carrying out geometric correction and then reprojection to conform to the other dataset.

\subsection{Digital Image Processing}

A data path was created to have shortcut link to the predefined data folder. A data path Created was for both input and output storage. The short cut provided faster access to the folder containing data and exporting the result after processing.

The images were visualized in Erdas Imagine Ver.10.0 and Envi ver.5.0 software's graphic user interfaces to ascertain the coverage and symbology. The metadata properties from the data information file were also visualized. 


\section{International Journal of Science and Research (IJSR) \\ ISSN (Online): 2319-7064}

Index Copernicus Value (2013): 6.14 $\mid$ Impact Factor (2014): 5.611

i. Supervised classification method was used based on five classes namely bare-ground, forest, vegetation, crops, buildup areas and water. This was done because of minimal in variation in the forest, crop and vegetation classes.

\subsection{Optimal Routing for water utilities}

This involved various data manipulations as follows;

\section{a. Model builder}

Model Builder was used in constructing and executing ArcGIS toolset workflows such reclassification, buffering, clipping among other functionalities. It was also be used for extending ArcGIS functionalities by allowing one to create and share models as tools. The model was developed and is shown in figure

\section{b. Reclassification}

This was done to change the cell value with new one based on new information, to put certain groups together, to scale or even to set new specific value.

\section{c. Multi-criteria Decision Method}

It involved use of Multi-criteria decision (MCDM) making process. The maxim of MCDM was employed because it is better for stakeholders to argue in principle about the merits of different factors and how their impacts should be measured than to argue in practice about alternative decision. The use of analytical hierarchy process (AHP) as proposed by Thomas saaty which focus on the capturing each stakeholder's view to give appropriate weight was used. Use Geo-statistical analysis to create continuous surface from sparse measurement taken at a sample point. This function was used to predict value using various GIS methods. This was used to compute statistical estimates such as the error, threshold and probability modeling.

Table 1: Random indices ( Saaty, 1977)

\begin{tabular}{|c|c|c|c|c|c|c|c|c|}
\hline $\mathrm{n}$ & 3 & 4 & 5 & 6 & 7 & 8 & 9 & 10 \\
\hline RI & 0.58 & 0.9 & 1.12 & 1.24 & 1.32 & 1.41 & 1.45 & 1.49 \\
\hline
\end{tabular}

Table 2: Classes and score developed

\begin{tabular}{|l|c|l|}
\hline Factor & Score & Class \\
\hline Distance from existing roads(m) & & \\
\hline $0-15$ & 1 & Suitable \\
\hline $15-30$ & 2 & Less Suitable \\
\hline$>30$ & 3 & Least Suitable \\
\hline Population(people/SqKm) & & \\
\hline $81-62$ & 1 & Suitable \\
\hline $43-61$ & 2 & Less Suitable \\
\hline $25-42$ & 3 & Least Suitable \\
\hline Markets/trading centers(meters) & & \\
\hline $0-1000$ & 1 & Suitable \\
\hline $1000-3000$ & 2 & Less Suitable \\
\hline$>3000$ & 3 & Least Suitable \\
\hline Schools(primary, secondary) & & \\
\hline $0-1000 \mathrm{~m}$ & 1 & Suitable \\
\hline $1000-3000 \mathrm{~m}$ & 2 & Less Suitable \\
\hline$>3000 \mathrm{~m}$ & 3 & Least Suitable \\
\hline Slope(degrees) & & \\
\hline $0-19$ & 1 & Least Suitable \\
\hline $19-39$ & 2 & Less Suitable \\
\hline $39-58$ & 3 & Suitable \\
\hline
\end{tabular}

\begin{tabular}{|l|c|l|}
\hline Factor & Score & Class \\
\hline Soil & & \\
\hline $0-2$ & 1 & Least Suitable \\
\hline $2-5$ & 2 & Less Suitable \\
\hline $5-8$ & 3 & Suitable \\
\hline Temperature $\left({ }^{\circ} \mathbf{C}\right)$ & & \\
\hline $25-27$ & 1 & Suitable \\
\hline $27-28$ & 2 & Less Suitable \\
\hline $28-30$ & 3 & Least Suitable \\
\hline Rainfall(mm) & & \\
\hline $920-989$ & 1 & Suitable \\
\hline $1989-1060$ & 2 & Less Suitable \\
\hline $1060-1171$ & 3 & Least Suitable \\
\hline Land Use(Acres) & & \\
\hline $0-2000$ & 1 & Not Suitable \\
\hline $2000-3000$ & 2 & Less Suitable \\
\hline $3000-4000$ & 3 & Suitable \\
\hline$>4000$ & 4 & Most Suitable \\
\hline Rivers & & \\
\hline $0-15$ & 1 & Least Suitable \\
\hline $15-30$ & 2 & Less Suitable \\
\hline$>30$ & 3 & Suitable \\
\hline
\end{tabular}

\section{Analysis, Results, and Discussion}

\subsection{Topographical Survey maps}

The topographical maps were obtained from survey of Kenya, scanned and using ArcGIS software geo-referenced. A clip shapefile was created to help in clipping the marginal information to visualize the continuity of features such as the roads, contours and the rivers among other features as shown in figure 3.

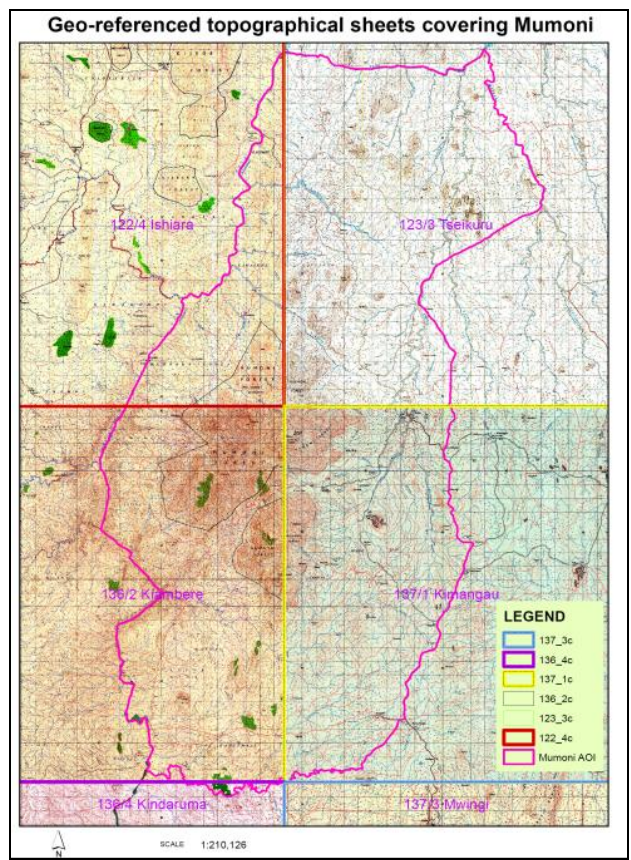

Figure 3: Topographical map sheet 


\section{International Journal of Science and Research (IJSR) \\ ISSN (Online): 2319-7064}

Index Copernicus Value (2013): 6.14 $\mid$ Impact Factor (2014): 5.611

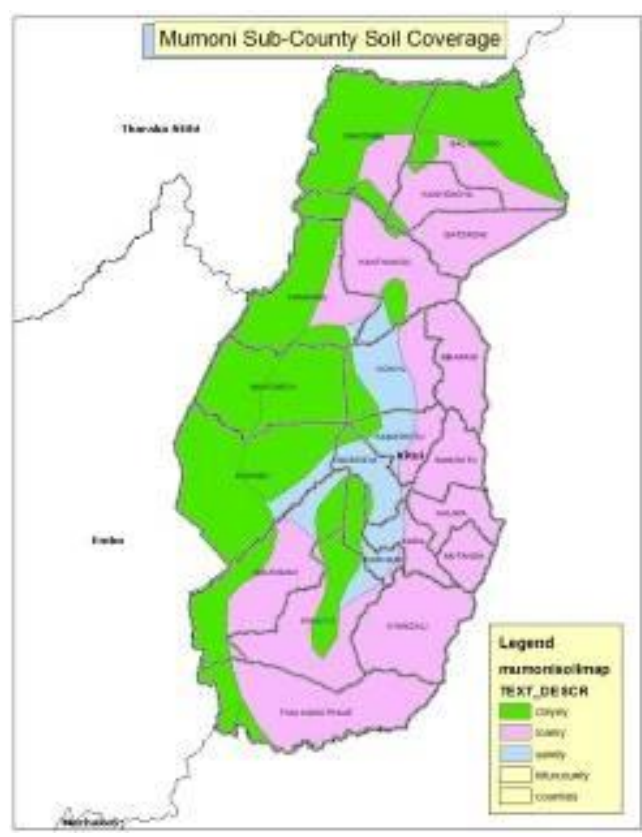

Figure 4: Soil Data of The Study Area

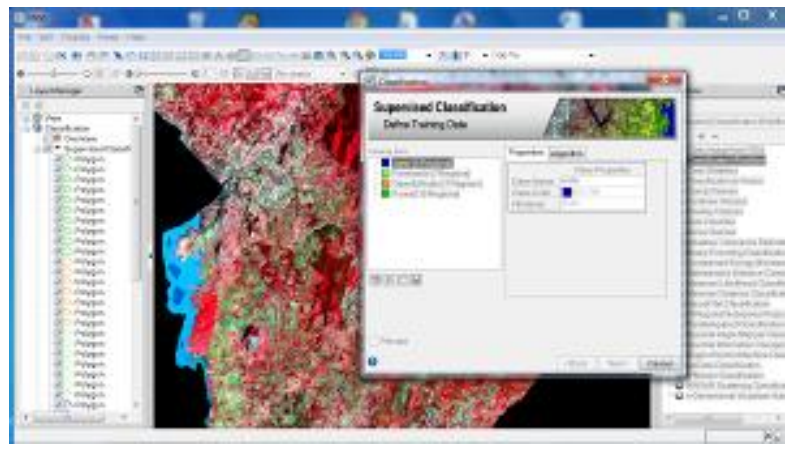

Figure 5: Supervised classification

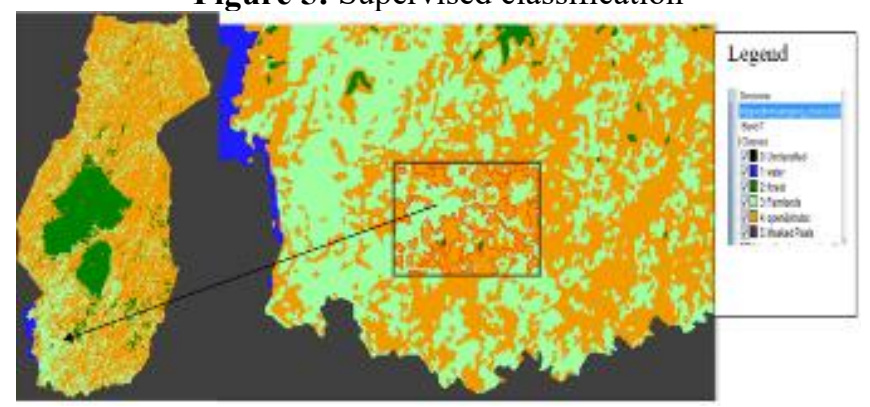

Figure 6: Classified land use and vector swipe

Table 3: Class Distribution Summary

\begin{tabular}{|c|c|c|c|}
\hline class & points & percentage & Area in Meters $\left.{ }^{2}\right)$ \\
\hline Unclassified: & 0 & $0.000 \%$ & $(0.0000$ \\
\hline water: & 12119 & $0.116 \%$ & 10921526.4576 \\
\hline Farmlands: & 277423 & $2.653 \%$ & 250010944.3392 \\
\hline Open\& Shrubs: & 760841 & $7.275 \%$ & 685662605.1264 \\
\hline Forest: & 138359 & $1.323 \%$ & 124687802.5536 \\
\hline Masked Pixels: & 9269427 & $88.633 \%$ & 8353518625.9008 \\
\hline
\end{tabular}

Table 4: Percentages of land cover land use in the study area

\begin{tabular}{|c|c|c|c|}
\hline Class & Points & $\mathbf{\%}$ & Meters $\left.^{2}\right)$ \\
\hline Unclassified: & 740,370 & $38.38 \%$ & $(667,214,336.4480$ \\
\hline water: & 12,119 & $0.63 \%$ & $(10,921,526.4576$ \\
\hline Farmlands: & 277,421 & $14.38 \%$ & $(250,009,141.9584$ \\
\hline Open\&Shrubs: & 760,841 & $39.44 \%$ & $(685,662,605.1264$ \\
\hline Forest: & 138,359 & $7.17 \%$ & $(124,687,802.5536$ \\
\hline
\end{tabular}

\subsection{Cross-referencing}

The classified land use generated compared well with the topographical map and Google images as shown in figure 7, 8.

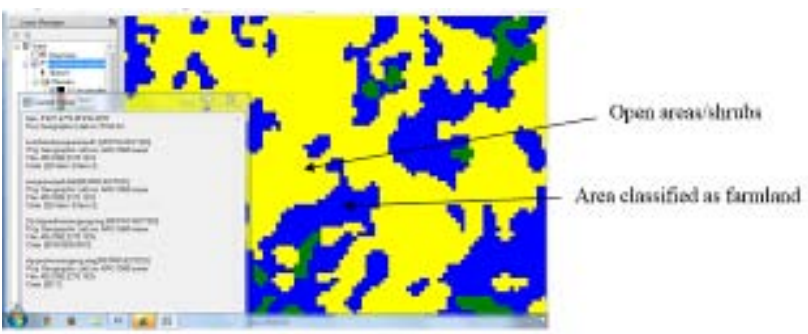

Figure 7: Results of Classified land use

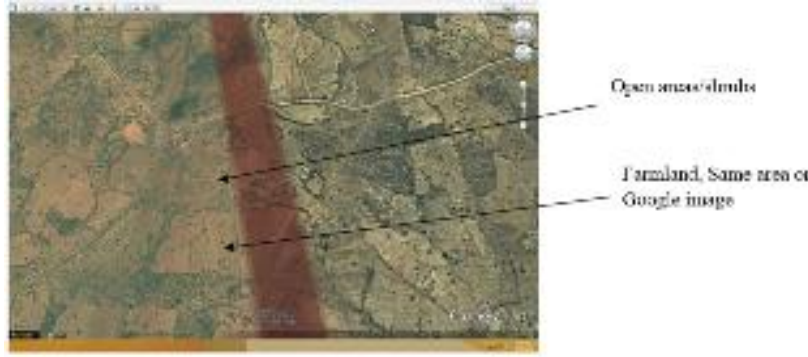

Figure 8: Cross-referencing using Google earth

\subsection{Datasets for carrying out weighted overlay}

The various data set were projected to Universal Transverse Mercator System (UTM) to have one projection systems to be able to carry analysis. The UTM was preferred because of ease in computation of distances (Euclidean) in some datasets. Since most of the existing data in the study area were in UTM as the National Mapping system covering the area of study, it was reasonable to adopt the National Mapping system. The Vector data were converted to raster by use of data conversion in the arc toolbox.

Datasets of roads, rivers, rainfall, temperature, waterlines, soils, land use, markets, population and slope were used in optimal routing and samples as show in figure 9, 10 and 11

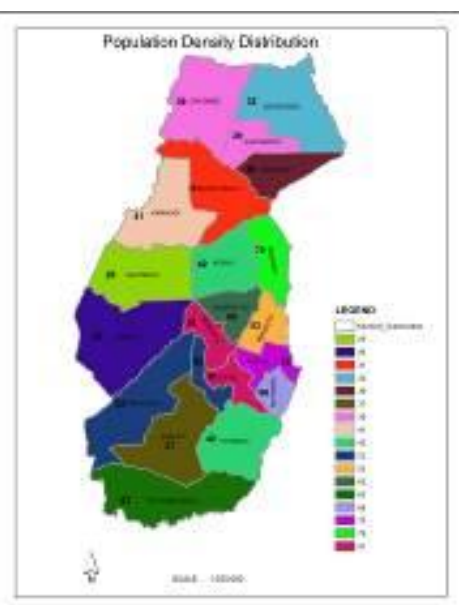

Figure 9: Population Density 


\section{International Journal of Science and Research (IJSR) \\ ISSN (Online): 2319-7064}

Index Copernicus Value (2013): 6.14 $\mid$ Impact Factor (2014): 5.611

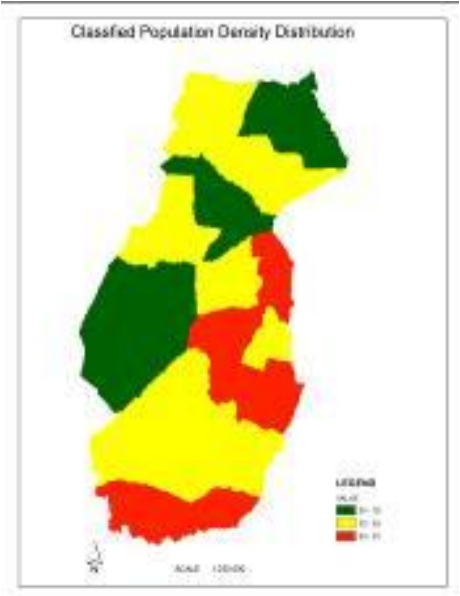

Figure 10: Classified Population Density

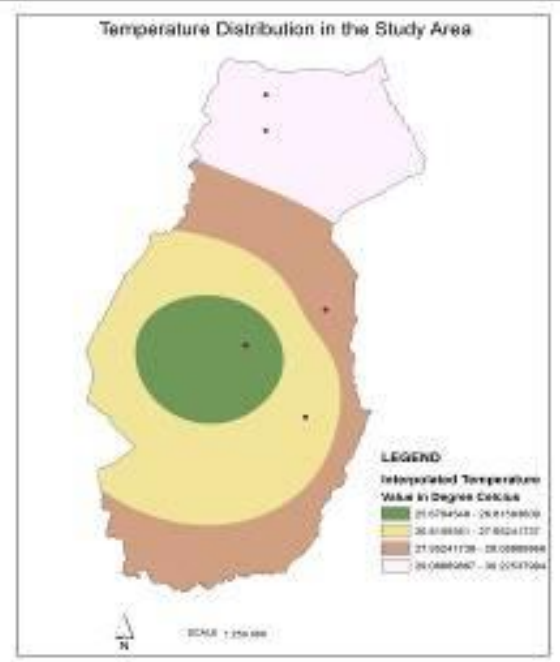

Figure 11: Temperature distribution

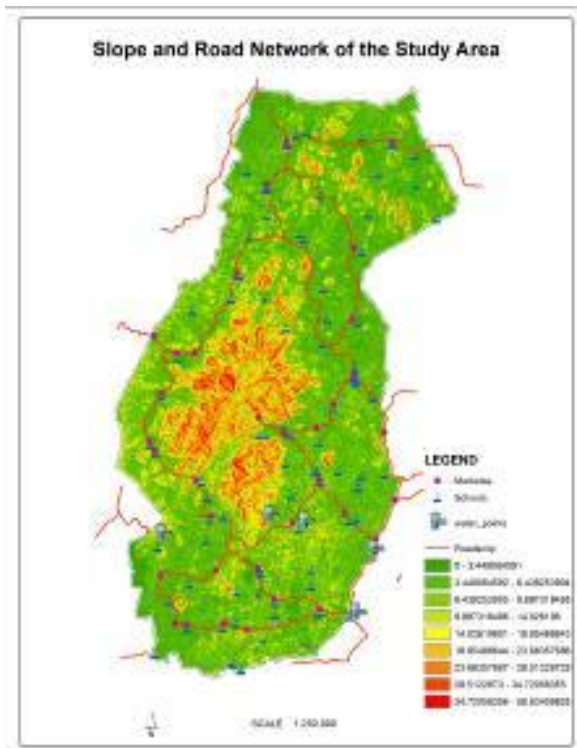

Figure 12: Slope and other features

\subsection{Optimal Routing for water}

This involved several processes, an AHP MCDM was used to deduce weights. The least cost surface by use of Cost Distance and Cost Path tool in the ArcGIS software. Use Analytical Hierarchy Process (AHP) Multi-criteria Decision making method. The various factor and data sets were formulated in the questionnaire and the expert opinions were considered. The figure 5 below show the AHP computation process to deduce the weights and check the quality of expert's judgment. From the field questionnaires the judgment matrix was tabulated. The judgment matrix was normalized using excel package to compute the priority vector (weights) for each factor, the principle Eigen values. The Eigen values were used to compute the maximum Eigen value $\left(\lambda_{\max }\right)$. The maximum Eigen value was used to compute the Consistency Index and consistency Ration

\subsection{Creating the Cost Surface Dataset}

An analytical hierarchy process was done yielding Consistency Ratio of 0.2452 . Normalizing the quality information gathered by the field questionnaire, the weight for the various factors identified was computed

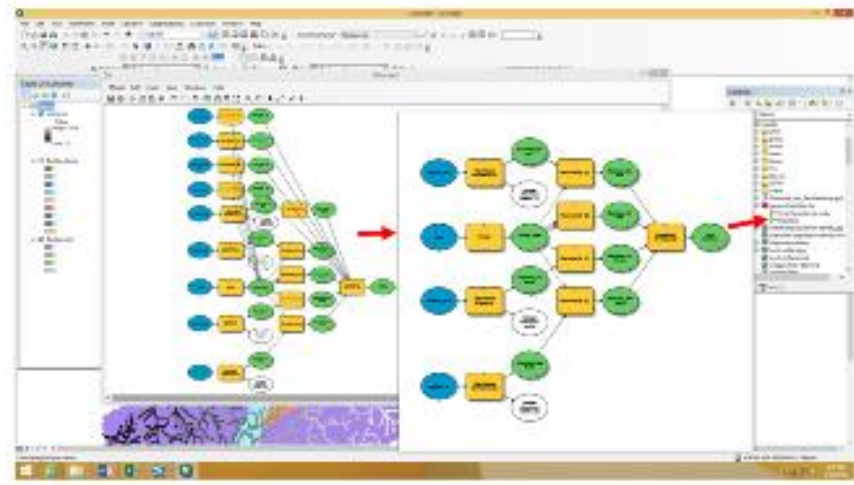

Figure 13: Classified Population Density

The figure 13 shows the cost surface suitability map of the study area. It contains seven layers representing region based on suitability scale 3 to 9 overlaid with the existing water points and schools. The scale 3 to 5 are the most suitable while scale is the least suitable.

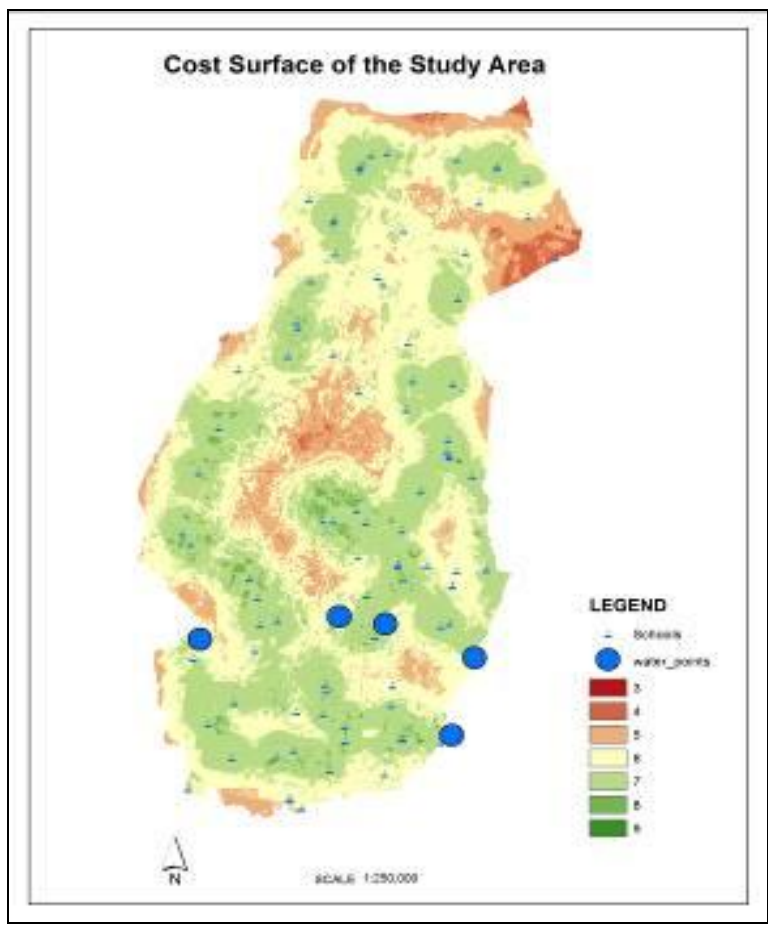

Figure 15: Cost Surface layer from the weighted overlay 


\section{International Journal of Science and Research (IJSR) \\ ISSN (Online): 2319-7064 \\ Index Copernicus Value (2013): 6.14 | Impact Factor (2014): 5.611}

The input layer in the cost distance are the cost surface and source layer (water tanks). Output from the cost distance are used together with the destination layer (schools) to generate the least cost from the nearest water source to every school

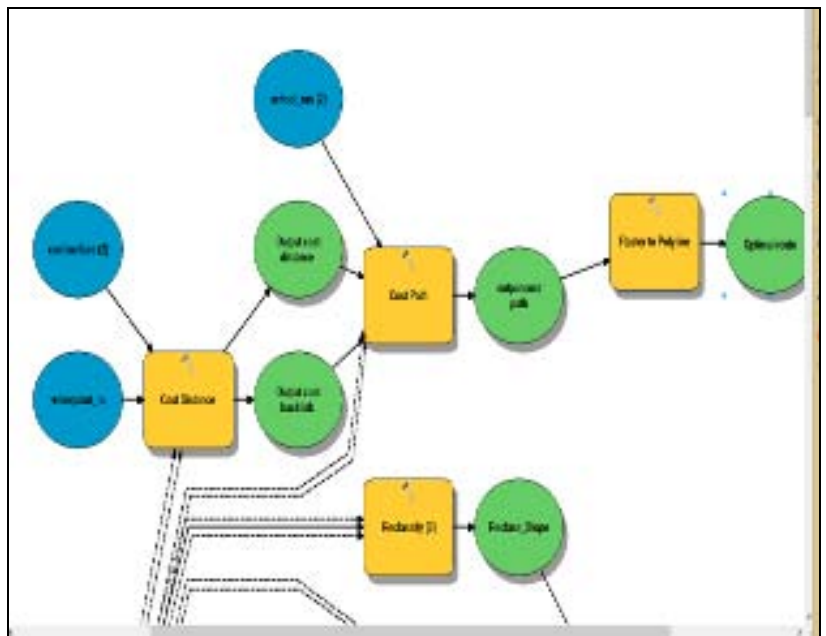

Figure 14: The Cost Surface Model

\section{Generating The Least Cost Path}

First the cost distance tool was used to compute the cumulative least cost of travelling from the cell to the source and a backlink dataset to give the direction of least costly path from the cell back to the source.finally the cost path tool utiliesd the output form cost diatnce to determine the optimal routes from the source to all the schools in the study area as show in figure 15

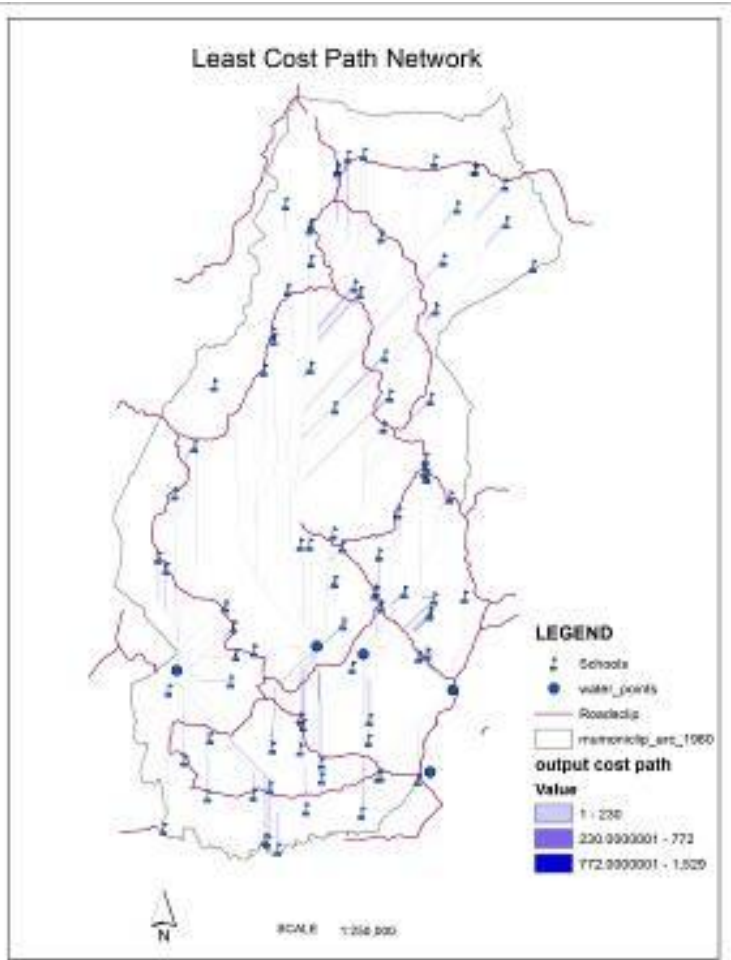

Figure 16: Final Computed Least Cost Path Visa-vis Schools

\section{Conclusion and Recommendation}

AHP, an MCDM method was used to generate judgment matrix based on the opinion of experts' qualitative measurements for various factors considered in the study as documented in the questionnaires. The Consistency Index obtained from the normalized matrix was $\mathrm{CR}=0.35552$ while the Consistency Ratio computed was $\mathrm{CR}=0.24518$.

A geodatabases consisting of various layers considered was developed and used to model the optimal routes to provide water to all picked existing schools. A cost surface raster layer was generated by combining the various reclassified datasets by carrying out weighted overlays which was then used to model the Optimal routes (least cost path) by setting the existing reservoirs (water tanks) as the source layer and the schools as the destination layer. From the research, it was established that the existing water line serves the lower region only and the reservoirs (storage tanks) are located approximately about $10 \mathrm{~km}$ apart. Finally, this research has established that AHP MCDM method and GIS technologies can be used to model the optimal routes for waterlines to provide information to decision makers. Through these technologies a more scientific, convenient and cost effective tools in modeling optimal routes has been realized and can further be used in efficient and effective management of water supply systems.

I recommendation further research to be done to establish additional water reservoirs (water tanks) to cover the area adequately from which new optimal water route network should be established.

Taking consideration from the previous studies, this area has minimal ground water potential this study can be used to model a means of extracting water from river tana for irrigation by gravity to spur development in the region. .This will greatly reduce the cost of pumping water for domestic, industrial and irrigation use.

The research has shown that use of GIS technologies provide useful information for decision makers geared towards spurring socio-economic development. The use AHP -GIS method should be used for all geospatial related project especially dealing with routing as a first step in design and construction. This will have a significant impact on sustainable development.

\section{References}

[1] 2009 Kenya Population and Housing Census Volume IA. Nairobi: Kenya National Bureau of Statistics.

[2] Balaghi, R. e. (2010). Managing Climatic Risks for Enhanced Food Security:Key Information Capabilities. Procedia Environmental Sciences 1 (pp. 313-323). Corresponding author. Tel: +212-5-37208770: Elsevier.

[3] DIAO, X., ZENG, S., \& WU, H. (2009). Evaluating Economic Benefits of Water Diversion Project for Environmental Improvement: A Case Study. J Water Resource and Protection, 1,1-57.

[4] Fenqin, Y. J. (2011). Researching the Relationship betweenthe Change of Vegetation Cover and Runoff Based on RS and GIS. 2011 International Conference on Environmental Science and Engineering(ICESE 2011), (p. 1). Tianjin China. 


\section{International Journal of Science and Research (IJSR) \\ ISSN (Online): 2319-7064}

Index Copernicus Value (2013): 6.14 | Impact Factor (2014): 5.611

[5] Hala, A. E., \& Ossman, A. H. (2013). Designing and evaluation of three alternatives highway routes using the analytical Hierarchy Process and the least cost analysis,application in Sinai Peninsula,Egypt. The Egyptian Journal of Remote sensing and Space Sciences, 141-151.

[6] Kuria, D. N., Gachari, M. K., Macharia, M. W., \& Mungai, E. (january 2012). mapping groundwater potential in kitui District,Kenya using Geospatial technologies. International Journal of water resources and Environment Engineering, 15-22.

[7] Longley, P. A., Goodchild, M. F., Maguire, D. J., \& Rhind, D. W. (2011). Geographic Information sysytems \& science. Hoboken USA: John Wiley \& Sons,Inc.

[8] Macharia, P. M., Mundia, C. N., \& Wathuo, M. W. (2015). Experts' responses Comparison in a GIS-AHP oilpipeline route optimization: A Statistical approach. American Journal of Geaographic Information System 2015,4(2), 53-63.

[9] Mati, B. M., Muchiri, J. M., Njenga, K., Penning de Vries, F., \& Merrey, D. J. (2005). Assessing water availability under pastoral livestock systems in droughtprone Isiolo District,Kenya. Pretoria, South africa: International Water management Institute(IWMI).

[10]Naik, G., Basavaraj, K. P., Hedge, V. R., Paidi, V., \& Subramanian, A. (2013). Using Geospatial technology to strengthen data systems in developing countries:. Applied Geography, 99-112.

[11] Nyambod, E. M., \& Nazmul, H. (2010,2). Integarted Water Resources Management and Poverty Eradicationpolicy Analysis of Bangladesh and Cameroon. J.water Resource and Protection, 191-198.

[12]P.Nilawar, M. W. (Vol.3,Issue 5, may2014). Identification of Groundwater Potential Zone using Remote Sensing and GIS Technique. International Journal of Innovative Research in Science Engineering and Technology.

[13] Poeter, E., J, M., G, T., \& R, S. (2005). Guidance for Evaluation of Potential Groundwater Mounding Asspciated with Cluster and High-Dnsity Wastewater Soil Absorption systems. International Groundwater Modelling Center, 2-45.

[14] Rosegrant, M. W., \& Cai, X. (June 2002). Global water demand and supply part2.results and prospects. international water Resource Association, 170-182.

[15] Shukla, P. C., \& Radadiya, B. (March 2013). Usage of GIS,GPS and Remote Sensing Data to identify effective and otimu route of development projects like Road,Train and Canal for better governance implementation. Indian Journal of applied Research.

[16] Suresh Babu, A. V., Shanker, M., \& Venkateshwar Rao, V. (2012). Satellite Derived geospatial Irrigation Performance Indicators for Benchmarking Studies of Irrigation Systems. Advances in Remote Sensing, 1,1-13.

[17] Trianntaphyllou, E., \& Mann, S. H. (1995). Using the Analytic Hierarchy Process for Decision Making in Engineering applications:Some challenges. International Journal of Industrial Engineering:Appliaction and Practice vol.2 No.1, 35-44.

[18] UNICEF East Asia and Pacific Regional Office. (2013). Water, Sanitation and Hygiene in Primary Schools in
South-East Asian Countries Realities,need and Recommendations. Thailand: UNICEF.

[19] Viswarani, C. D., Vijayakuma, R. D., Subbararaj, L., Umashankar, S., \& Kathirvelan, J. (2014). Optimization on shortest path finding for underground cable transmission lines routing using GIS. Journal of Theoretical and Applied Information Technology, Vol.65 NO.3.

[20] Yildirim, V., Yomralioglu, T., Nisanci, R., Erbas, Y. S., \& Bediroglu, S. (n.d.). Natural Gas Transmission Route Selection Using GIS and AHP. Scientific and Technological Research Council of Turkey.

\section{Author Profile}

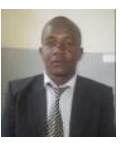

Peter W.Kathuo is Senior Land Surveyor working with the Government of Kenya. He has worked over ten years in government. Apart from working major project in the government he initiated formulation of Rapid Response Survey Teams (RRSTs) geared towards fast-tracking the process registration of land tenure in Kenya through applying the new technologies."New technology new thinking and new way of doing things" is slogan of RRSTs towards social tenure domain model. Mr. Kathuo hold B.Sc. in Surveying from University of Nairobi. In the year 2004-2006 he worked a site surveyor in construction industry before joining the ministry of Land, Housing and Urban Development, Nairobi Kenya up to date. He has also trained and attended several workshops among them are the GIS course(India 2010),capacity Building course for National mapping Agencies in soul, South Korea 2013

Kenneth Mubea has wide knowledge of Geomatics, GIS and Remote sensing and their applications in numerous fields. $\mathrm{He}$ is a Lecturer at Dedan Kimathi University of Technology, Nyeri, Kenya. He holds a Bachelor's degree in Geomatic Engineering from Jomo Kenyatta university of Agriculture and technology (Kenya), an MSc degree in GIS and Remote Sensing from Jomo Kenyatta university of Agriculture and technology (Kenya) and a PhD in Remote Sensing \& GIS from University of Bonn (Germany). He has authored many papers and attended various international conferences. His interests are urban growth modeling, remote sensing, cellular automata, GIS, Land information systems (LIS), surveying, Geodesy, web mapping among other related disciplines in Geomatics. 